\title{
SUOMALAISTEN NUORTEN YKSILÖLLISTYVÄT KULTTUURIVALINNAT
}

\section{Individualized cultural choices of Finnish adolescents}

The purpose of this article is to examine how social background variables and individual preferences impact on Finnish adolescents highbrow orientation. The data of the article is Youth barometer $(n=1900)$ from the year 2009. Social background variables are gender, age, educational level of the adolescent, residential area, parent's educational level and parent's cultural resources. Individual preferences are measured by the number cultural hobbies and art preferences of the adolescent. The methods are one-way analysis of variance, multiple classification analysis and discrimination analysis. According to the results individual preferences are more powerful determinants than social background variables in explaining adolescents highbrow orientation. Several cultural hobbies and open-minded approach towards various meanings of the art were found to be the most explanatory variables. The results are similar to recent studies which underline the impact of cultural practices and preferences for individuals cultural choices. In addition family background is less significant factor for adolescents highbrow orientation than it is claimed.

Keywords: cultural choices of adolescents, highbrow culture, quantitative methods

\section{Johdanto}

Yhteiskuntatieteellisessä tutkimuksessa käydään jatkuvaa keskustelua elämäntyyleistä ja niiden muodostumiseen vaikuttavista tekijöistä. Tyypillisenä lähestymistapana on näkemys, jonka mukaan yksilöiden elämäntyylit ovat sidoksissa erityyppisiin sosiaalisiin taustatekijöihin, kuten sosiaaliseen asemaan (Bourdieu, 1984, s. 56), ikään (Roose, van Eijck \& Lievens, 2012) tai sukupuoleen (Christin, 2012). Sosiaalisia tekijöitä korostaville näkemyksille on myös esitetty vastakkaisia näkemyksiä. Erityisesti viimeaikaisissa tutkimuksissa on alettu korostaa entistä voimakkaammin yksilöiden omien valintojen ja merkityksenantojen roolia elämäntyyliensä rakennusaineina (Daenekindt \& Roose, 2013; Hanquinet, 2013; Lahire, 2008).

Vastaavanlaiset lähestymistapojen erot ovat rantautuneet myös nuorten kulttuurivalintojen muodostumisesta käytävään keskusteluun. Erityisesti korkeakulttuurista, kuten kuvataiteesta tai klassisesta musiikista, kiinnostuneiden ja sitä kuluttavien nuorten kulttuurivalintoja lähestytään erilaisten sosiaalisten tekijöiden kautta. Tyypillisesti nuoren korkeakulttuurista suuntautumista selitetään heidän vanhempiensa koulutuksella ja kulttuurin harrastamisella (Nagel, 2010; Willekens \& Lievens, 2014), nuoren sukupuolella (van Wel, Couwenbergh-Soeterboek, Couwenbergh, ter Bogt \& Raaijmakers, 2006) tai koulutuksella (Nagel \& Ganzeboom, 2002).

Vaikka näkemys sosiaalisten tekijöiden merkityksestä on säilynyt vahvana, niin joidenkin nuorisotutkijoiden mukaan (esim. Salasuo, 2006, s. 31) 2000-luvun nuorten elämäntyylejä leimaa atomisoituneisuus, jolloin perinteisten 
sosiaalisten tekijöiden merkitys nuorten elämäntyylillisiin valintoihin olisi aikaisempaa heikompaa. Esimerkiksi vanhemmilta saatujen vaikutusten sijaan nuoret saavat virikkeitä elämäntyyleihinsä muun muassa kavereiltaan tai internetistä. Myös korkeakulttuurista kiinnostuneiden nuorten tutkimuksissa on havaittu, että sosiaalisten tekijöiden lisäksi heitä yhdistää erityyppiset yksilölliset valinnat kuten samanlaiset vapaa-ajan viettotavat (van Wel, Couwenbergh-Soeterboek, Couwenbergh, ter Bogt \& Raaijmakers, 2008) tai yhdenmukainen musiikkimaku (Tanner, Asbridge \& Wortley, 2008).

Tämä artikkeli ottaa osaa edellä kuvattuun keskusteluun tarkastelemalla korkeakulttuuriin suuntautuneiden nuorten kulttuurivalintojen muodostumiseen vaikuttavia tekijöitä. Artikkelissa tutkitaan, miten sosiaaliset taustatekijät ja yksilölliset valinnat vaikuttavat suomalaisten 15-29-vuotiaiden nuorten korkeakulttuuriseen suuntautumiseen, jota mitataan korkeakulttuuria edustavien kulttuuri- ja taidelaitosten tärkeinä pitämisen näkökulmasta. Aineistona käytetään vuoden 2009 Nuorisobarometriä, jonka vastaajien määrä on 1900. Tutkimuksen analyysimenetelmiä ovat yksisuuntainen varianssianalyysi, moniluokitteluanalyysi sekä erotteluanalyysi. Artikkelini pohjautuu keväällä 2014 Jyväskylän yliopistossa hyväksyttyyn pro gradu -tutkielmaan (Räisänen 2014).

\section{Luokkamausta yksilöllisiin kulttuurivalintoihin}

Korkeakulttuurin kuluttamista koskevassa tutkimuksessa keskitytään tyypillisesti koko väestöä koskeviin tilastoaineistoihin rajatun ikäryhmän, kuten nuorten, sijaan. Tämän vuoksi luon aluksi lyhyen katsauksen siitä käytävään ajankohtaiseen keskusteluun, jonka jälkeen esittelen nuorten korkeakulttuuriinkuluttamisesta tehtyä tutkimusta.

Länsimaissa koulutusastetta on pidetty tyypillisenä yksilön sosiaalisen aseman ilmaisimena (Bourdieu, 1984, s. 26). Mitä kouluttautuneempi yksilö on, sitä korkeampi on hänen asemansa sosiaalisessa hierarkiassa. Myös yksi- lön kulttuurimaun ja -kulutuksen ajatellaan ilmentävän niin lapsuuden (Bourdieu, 1984, s. 13; van Eijck, 1997) kuin myöhempien elämänvaiheiden sosiaalista asemaa (esim. Daenekindt \& Roose, 2014). Kiinnostus tietyntyyppisiä kulttuurituotteita kohtaan yhdistää samanlaisessa sosiaalisessa asemassa olevia. Samalla yhdenmukaiset kiinnostuksenkohteet luovat symbolisia eroja eri yhteiskuntaluokkien välille. (Bourdieu, 1984, s. 171-172.)

Vallitseva käsitys sosiaalisen aseman yhteydestä yksilön kulttuurivalintoihin on kuitenkin asetettu entistä kyseenalaisemmaksi. Sosiaalisen aseman ohella muilla sosiaalisilla tekijöillä näyttää olevan aikaisempaa voimakkaampi vaikutus yksilön kulttuurivalintojen muodostumiseen, minkä sosiaalisen aseman roolia korostava näkökulma sivuuttaa (Hanquinet, 2013; Lahire, 2008). Lisääntynyt korkeakoulutus ja sosiaalinen liikkuvuus ovat heikentäneet ylempien sosiaaliryhmien tarvetta erottautua alemmista sosiaaliryhmistä kulttuurivalintojensa kautta (Peterson \& Kern, 1996; van Eijck \& Knulst, 2005). Tämän seurauksena kulttuurivalintojen lähestyminen yksinomaan sosiaalisen aseman näkökulmasta antaa yksiulotteisen kuvan niiden muodostumiseen vaikuttavista tekijöistä.

Uudempien tutkimusten mukaan muun muassa sukupuoli (Christin, 2012) tai ikä (van Eijck \& Knulst, 2005; Hanquinet, 2013) selittää entistä vahvemmin yksilöiden kulttuurimaun ja kulttuurinkulutuksen eroja. Tämä näkyy myös korkeakulttuurista kiinnostuneiden kulttuurivalinnoissa, joita sosiaalinen asema selittää aikaisempaa heikommin. Esimerkiksi Suomessa korkeakulttuurista makua edustavat ja korkeakulttuuria kuluttavat pääsääntöisesti naiset ja iäkkäämmät väestöryhmät (Rahkonen \& Purhonen, 2004; Alasuutari, 2009).

Samaan aikaan kulttuurisosiologisessa tutkimuksessa on alettu huomioida erityyppisten yksilöllisten valintojen merkitys. Tietyntyyppistä kulttuuria kuluttavien, kuten taidemuseoissa käyvien, kulttuuriset mieltymykset ja kiinnostuksenkohteet eivät edusta minkään tietyn yhteiskuntaluokan kulttuurimakua (Hanquinet, 2013). Sosiaalisesti ja kulttuurisesti monimuotoisessa yhteiskunnassa yksilön kulttuurivalin- 
nat vaihtelevat elämänkulun aikana sekä erilaisissa sosiaalisissa tilanteissa (Lahire, 2008). Lisäksi teknologian kehittyminen on mahdollistanut konserttien katsomisen tai taideteoksiin tutustumisen internetin välityksellä, mikä on osaltaan muuttanut kulttuurinkulutuksen tapoja entistä yksilöllisemmiksi (Gripsrud, Hovden \& Moe, 2011).

\section{Nuorten korkeakulttuuristen valintojen muodostuminen}

Nuorten kulttuurivalintojen tutkimuksessa painottuu sosiaalisia tekijöitä korostava lähestymistapa, mikä näky erityisesti korkeakulttuurista kiinnostuneiden nuorten tutkimuksessa. Nuoren korkeakulttuurisen suuntautumisen muodostumiseen nuoren perhetaustalla ajatellaan olevan keskeinen merkitys. Erityisesti korkeasti koulutettujen vanhempien lapset erottuvat korkeakulttuurin kuluttajina (Nagel, 2010; Willekens \& Lievens, 2014). Lisäksi vanhempien oma kulttuurinen kiinnostuneisuus, kuten kulttuurinkulutus ja harrastaminen, vaikuttavat nuoren kulttuurisen suuntautumisen muodostumiseen. Korkeakulttuurista kiinnostuneille nuorille on tyypillistä kulttuuritapahtumissa ja taidelaitoksissa käyvät vanhemmat (Nagel, Damen \& Haanstra, 2010). Usein tällaiset vanhemmat käyvät niissä yhdessä jälkikasvunsa kanssa (Tolonen, 2013). Lisäksi taiteesta ja kulttuurista kiinnostuneet vanhemmat kannustavat jälkikasvuaan taide- ja kulttuuriharrastusten pariin (Scherger \& Savage, 2010). Näin ollen vanhemmilta saadut kulttuuriset resurssit edesauttavat nuorta sisäistämään vanhempiensa kulttuuriset kiinnostuksenkohteet.

Perhetaustan lisäksi nuorten korkeakulttuurisen kiinnostuksen ajatellaan kytkeytyvän muihin sosiaalisiin tekijöihin. Koulutusasteella ja -alalla näyttäisi olevan yhdenmukainen vaikutus nuorten kulttuurivalintoihin. Erityisesti korkeammin kouluttautuneet nuoret käyvät muita nuoria aktiivisemmin kulttuurija taidelaitoksissa (Nagel, 2010; Willekens \& Lievens, 2014). Lisäksi humanistisia tieteitä opiskelevat ovat kiinnostuneempia korkeakult- tuurista ja taiteesta kuin kauppa- tai luonnontieteitä opiskelevat (Gripsrud ym., 2011).

Nuorten kulttuurivalinnoissa havaitaan myös sukupuolen mukaisia eroja. Erilaisissa kulttuurilaitoksissa käyminen on yleisempää nuorille naisille (van Wel ym., 2006). Lisäksi he pitävät enemmän korkeakulttuuriksi mielletyistä musiikkityyleistä, kuten klassisesta musiikista ja oopperasta (Tanner ym., 2008).

Myös nuorten kulttuurivalintojen tutkimuksessa on alettu suhtautua aikaisempaa kriittisemmin sosiaalisia tekijöitä korostaviin näkemyksiin. Esimerkiksi perhetaustan voimakkuutta vastaan puhuvat väitteet nuorten elämätyylien atomisoitumisesta. Tällöin ajatellaan, että esimerkiksi vanhempien koulutuksen merkitys nuoren kulttuurivalintojen muodostumiseen on aiempaa heikompaa (Salasuo, 2006, s. 31). Nuoret saavat vaikutteita kulttuuristen tyyliensä rakentamiseen vanhempiensa lisäksi muun muassa kavereiltaan (Tolonen, 2013; van Wel ym., 2006). Yhä enemmän esitetään tutkimustuloksia siitä, että yksilöiden kulttuurivalintoja selittävät pikemminkin erilaiset elämäntilanteet ja sosiaaliset kontekstit kuin pelkkä perhetausta (esim. Daenekindt \& Roose, 2014).

Korkeakulttuurista kiinnostuneiden nuorten tutkimuksessa on alettu kiinnittää huomioita myös yksilöllisten valintojen merkitykseen. Tällaiset nuoret lukevat muita nuoria enemmän, harrastavat soittamista ja käyvät muita useammin musiikki- tai kuvataidekoulua (van Wel ym., 2008). Lisäksi korkeakulttuuriin suuntautuneita nuoria yhdistää yhdenmukainen suhtautuminen erilaisiin kulttuuri-ilmiöihin, mikä ilmenee kiinnostuksena erityyppisiin musiikkityyleihin (Tanner ym., 2008).

\section{Nuorten kulttuurivalintojen tutkiminen}

\section{Aineisto ja tutkimusmenetelmät}

Artikkelissa tutkin, miten sosiaaliset taustatekijät ja yksilölliset valinnat vaikuttavat suomalaisten nuorten korkeakulttuurisen suuntautumisen muodostumiseen. Tämän tutkimiseksi muodostin kaksi erillistä tutkimusasetelmaa. 
Niistä ensimmäisessä selvitän, mitkä tekijät ennustavat nuorten korkeakulttuurista suuntautumista. Toisessa tutkimusasetelmassa etsin tekijöitä, jotka erottelevat korkeakulttuuriin suuntautuneita nuoria niistä nuorista, jotka eivät ole kiinnostuneita korkeakulttuurista. Kahden eri tutkimusasetelman tavoitteena on lähestyä tutkittavaa ilmiötä tilastollisia menetelmiä hyödyntäen eri näkökulmista, mikä avaa ilmiötä huomattavasti moniulotteisemmin kuin pelkän yhden tutkimusasetelman käyttäminen.

Tutkimuksen aineistona on vuoden 2009 Nuorisobarometri $(\mathrm{n}=1900)$, jonka vastaajina ovat 15-29-vuotiaat suomalaiset nuoret, ahvenanmaalaisia lukuun ottamatta. Nuorisobarometri on joka vuosi kerättävä tutkimus, jossa selvitetään suomalaisten nuorten arvoja ja asenteita. Vuonna 2009 teemana oli taide ja kulttuuri.

Ensimmäisen tutkimusasetelman menetelminä käytän yksisuuntaista varianssianalyysia sekä moniluokitteluanalyysia. Yksisuuntainen varianssianalyysi kertoo, mitkä selittäviksi valituista muuttujista ovat yhteydessä selitettävään muuttujaan (Nummenmaa, 2010, s. 185). Muuttujien välinen yhteisvaihtelu ei vielä takaa niiden välistä todellista yhteyttä, vaan muuttujien väliset yhteydet on vakiotuiin käyttämällä moniluokitteluanalyysia. Se osoittaa, muuttuuko yksittäisen muuttujan yhteys selitettävään muuttujaan, kun selittäväksi muuttujaksi valitaan useita muuttujia (Jokivuori \& Hietala, 2007, s. 155-160). Moniluokitteluanalyysi tuottaa jokaiselle selittävälle muuttujalle standardoidun betakertoimen, joka kuvaa yksittäisen selittävän muuttujan suhteellista ennustuskykyä (mt., s. 167-169).

Toisen tutkimusasetelman menetelmänä käytän askeltavaa erotteluanalyysia, joka muodostaa selittäviksi valittujen muuttujien pohjalta erottelu-ulottuvuuden. Menetelmä jättää erottelu-ulottuvuudelle tutkittavia ryhmiä voimakkaimmin erottelevat muuttujat ja poistaa siitä ryhmiä erottelemattomat muuttujat. Erotteluanalyysi huomioi kolmannen tekijän vaikutuksen vakioimalla muuttujien väliset yhteydet. (Jokivuori \& Hietala 2007, s. 119, 122, 132.)

\section{Tutkimuksessa käytettävien muuttujien muodostaminen}

Korkeakulttuurisen suuntautumisen mittaamiseksi ei ole olemassa mitään yleisesti tunnustettua tapaa. Aikaisemmissa tutkimuksissa sitä on mitattu esimerkiksi korkeakulttuuria edustavien kulttuurinmuotojen kulutuksen ja pitämisen (Purhonen, 2011) sekä tärkeyden (Alasuutari, 2011) näkökulmista. Nuorten korkeakulttuurisen suuntautumisen mittarina käytän sitä, miten tärkeänä nuori pitää erilaisia kulttuuri- ja taidelaitoksia oman elämänsä ja vapaa-aikansa kannalta. Valittuja kulttuuri- ja taidelaitoksia ovat oopperaesitykset ja oopperajuhlat, taidemuseot ja taidenäyttelyt, kulttuurihistorialliset museot ja näyttelyt, teatteriesitykset, sinfonia- ja kamarimusiikkiesitykset sekä kulttuuri- ja taidetalojen palvelut, joita on aikaisemmin pidetty korkeakulttuuria edustavina kulttuuri-instituutioina (Peterson \& Kern, 1996: van Eijck \& Bargeman, 2004; van Eijck \& Knulst, 2005; Christin, 2012).

Ensimmäisessä tutkimusasetelmassa korkeakulttuurista suuntautumista lähestyn jatkuvana ilmiönä, joka voi saada minkä tahansa arvon minimi- ja maksimiarvojen väliltä. Tämän johdosta yksittäisistä kulttuuri- ja taidelaitoksista muodostetaan yksi keskiarvoestimoitu summamuuttuja, joka mittaa nuorten korkeakulttuurista suuntautumista. Summamuuttuja laskee yksittäisten kulttuuri- ja taidelaitosten havaintoarvot yhteen ja muodostaa niistä keskiarvon (Nummenmaa, 2010, s. 161). Muodostetun muuttujan vaihteluväliksi tuli 1-5. Mitä suuremman arvon summamuuttuja saa, sitä voimakkaampi on nuoren korkeakulttuurinen suuntautuminen. Korkeakulttuurista suuntautumista mittaava summamuuttuja on sisäisesti tarpeeksi yhtenäinen, sillä sen Cronbachin alfakerroin on 0,780 , joka on raja-arvona pidettyä 0,6:tta korkeampi (mt., s. 356).

Toisessa tutkimusasetelmassa korkeakulttuurista suuntautumista mitataan kahden ryhmän avulla, jotka muodostetaan k-keskiarvoklusterianalyysilla (Räisänen 2014, s. 62). Menetelmä etsii havaintojoukosta yhdenmukaisia havaintoyksikköjä ja muodostaa niistä 
ryhmiä (Nummenmaa 2010, s. 428). Ensimmäisessä ryhmässä olivat korkeakulttuuriin suuntautuneet nuoret. Tämän ryhmän havaintojen määrä oli 684. Jälkimmäisessä ryhmässä olivat nuoret, jotka eivät olleet suuntautuneet korkeakulttuuriin. Kyseisessä ryhmässä oli yhteensä 1216 havaintoa.

Tutkimuksen selittävät muuttujat muodostan erilaisista sosiaalisia taustatekijöitä ja yksilöllisiä valintoja mittaavista muuttujista. Sosiaalisia taustatekijöitä mittaavia muuttujia ovat nuoren sukupuoli, ikä, opiskelupaikka, asuinpaikan kuntatyyppi sekä vanhempien koulutusaste. Lisäksi vanhemmilta saatujen kulttuuristen resurssien vaikutusta mittasin taiteeseen tai muuhun luovaan toimintaan osallistumiseen kannustamisen näkökulmasta. Aikaisemmissa tutkimuksissa vanhemmilta saatuja kulttuurisia resursseja on mitattu jälkikasvunsa kulttuuriharrastuksiin kannustamista mittaavalla muuttujalla (esim. Scherger \& Savage, 2010). Tässä valittu muuttuja on likert-asteikollinen. Sen vastausvaihtoehtojen ensimmäisessä päässä on "Täysin riittävästi” ja toisessa päässä "Täysin riittämättömästi” vanhemmiltaan kannustusta taiteeseen tai muuhun luovaan toimintaan osallistumiseen saaneet nuoret.

Erilaisten yksilöllisten valintojen, kuten kulttuuristen mieltymysten tai kulttuurin harrastamisen, rooli on tullut entistä tärkeämmäksi osaksi kulttuurivalintojen muodostumista käsittelevää tutkimusta (Lahire, 2008; Daenekindt \& Roose, 2013; van Wel ym., 2008). Tässä yksilöllisiä valintoja mittaavista muuttujista ensimmäinen on nuoren kulttuuriharrastusten määrä. Tutkimukseen valitut kulttuuriharrastukset ovat: soittaminen, laulaminen, piirtäminen, kuvataide, valokuvaaminen, videokuvaaminen, sarjakuvien tekeminen, käsityöt, näytteleminen, tanssiminen, kuvien tekeminen tai käsitteleminen tietokoneella, musiikin tekeminen tietokoneella, sirkus, kulttuuritapahtumien järjestäminen ja graffitien tekeminen. Lisäksi yksilöllisiä valintoja mitattiin viidellä taiteeseen liittyvällä asenneväittämällä, joihin suhtautumista mitattiin myönteinen-kielteinen-ulottuvuuden kautta. Valitut asenneväittämät mittasivat nuoren taiteeseen suhtautumista eri näkökulmista.
Yksilöllisiä valintoja mittaavien muuttujien haasteena on, että nuoren kulttuuriharrastuksia tai taidemieltymyksiä voi selittää erilaiset sosiaaliset taustatekijät, kuten nuoren sukupuoli. Tässä käytettävien monimuuttujamenetelmien etuna on, että vakiointi eliminoi kolmannen tekijän vaikutuksen selittävän ja selitettävän muuttujan väliltä. Jos sukupuoli selittää nuoren kulttuuriharrastusten määrää, tällöin muuttujien vakioinnin seurauksena kulttuuriharrastamisen ja korkeakulttuurisen suuntautumisen välinen yhteys katoaa ja jäljelle jää ainoastaan sukupuolen ja korkeakulttuurisen suuntautumisen välinen yhteys.

\section{Yksilölliset valinnat ennustavat nuorten korkeakulttuurista suuntautumista}

Ensimmäisessä tutkimusasetelmassa selvitän, miten selittäviksi valitut muuttujat ennustavat nuorten korkeakulttuurista suuntautumista. Aluksi tarkastellaan, miten eri selittävät muuttujat ovat yhteydessä korkeakulttuuriseen suuntautumiseen. Menetelmänä käytän yksisuuntaista varianssianalyysia, jonka tulokset esitetään Taulukossa 1. Mitä korkeampi on muuttujan vastausvaihtoehdon ryhmäkeskiarvo, sitä voimakkaampi on muuttujan yhteys korkeakulttuuriseen suuntautumiseen.

Sosiaalisista taustatekijöistä korkeakulttuuriseen suuntautumiseen ovat yhteydessä vanhempien koulutusaste, nuoren asuinpaikka sekä vanhemmilta saatuja kulttuurisia resursseja mittaava muuttuja. Vanhempien koulutusasteen osalta korkeakulttuuriseen suuntautumiseen on yhteydessä molempien vanhempien yliopistotutkinto, sillä tällaisten nuorten ryhmäkeskiarvo on korkein. Kaupunkimaisissa kunnissa sekä taajaan asutuissa tai maaseutumaisissa kunnissa asuvat nuoret ovat korkeakulttuurisesti suuntautuneempia kuin pääkaupunkiseudulla asuvat nuoret. Vanhemmilta saaduilla kulttuurisilla resursseilla on vaikutusta nuorten korkeakulttuuriseen suuntautumiseen, sillä kannustusta "Täysin riittävästi" tai "Melko riittävästi” saaneiden nuorten keskiarvot ovat 
korkeimmat. Nuoren sukupuolella, iällä tai opiskelupaikalla ei ole yhteyttä tutkittavaan ilmiöön.

Yksilöllisiä valintoja mittaavista muuttujista kaikki ovat tilastollisesti erittäin merkitsevässä yhteydessä korkeakulttuurista suuntautumista mittaavaan summamuuttujaan. Kulttuuriharrastusten määrä on positiivisessa yhteydessä tutkittavaan ilmiöön, sillä nuorilla, joilla on vähintään kolme kulttuuriharrastusta, keskiarvo on eri vastausvaihtoehdoista korkein. Taiteeseen liittyvien asenneväittämien osalta yhteys korkeakulttuuriseen suuntautumiseen on yhdenmukainen. Nuoret, jotka suhtautuvat myönteisesti esitettyihin väittämiin, ovat korkeakulttuurisesti suuntautuneimpia, sillä taideväittämien kanssa "Täysin samaa" tai "Jokseenkin samaa mieltä" olevien nuorten keskiarvot ovat korkeimmat.

Moniluokitteluanalyysilla suoritettava muuttujien välisten yhteyksien vakiointi muuttaa hieman selittävien muuttujien yhteyttä korkeakulttuuriseen suuntautumiseen. Samalla nuoren asuinpaikkaa ja taiteen itseisarvoa mittaavan muuttujan yhteys korkeakulttuuriseen suuntautumiseen katoaa.

Taulukko 1. Sosiaalisten taustatekijöiden ja yksilöllisten valintojen yhteys korkeakulttuuriseen suuntautumiseen. (Taulukko jatkuu seuraavalle sivulle.)

$\begin{array}{llll}\text { Muuttuja } & \text { N } & \text { Keskiarvo Keskihajonta } \\ \text { Sukupuoli } & \end{array}$

\section{Sukupuoli}

\begin{tabular}{|c|c|c|c|}
\hline Nainen & 928 & 2,31 & 873 \\
\hline Mies & 972 & 2,36 & 936 \\
\hline \multicolumn{4}{|l|}{ lkä } \\
\hline 15-19-vuotiaat & 642 & 2,38 & 952 \\
\hline 20-24-vuotiaat & 617 & 2,34 & 891 \\
\hline 25-29-vuotiaat & 640 & 2,30 & 873 \\
\hline \multicolumn{4}{|c|}{ Opiskeleeko lukiossa tai korkeakoulussa } \\
\hline Kyllä & 406 & 2,38 & 915 \\
\hline $\mathrm{Ei}$ & 1494 & 2,33 & 903 \\
\hline \multicolumn{4}{|l|}{ Vanhempien koulutusaste ${ }^{* *}$} \\
\hline Ei yliopistotutkintoa & 1380 & 2,31 &, 885 \\
\hline Vain toisella vanhemmista yliopistotutkinto & 355 & 2,38 & 920 \\
\hline Molemmilla vanhemmilla yliopistotutkinto & 165 & 2,55 & 1,019 \\
\hline \multicolumn{4}{|l|}{ Asuinpaikka*** } \\
\hline Pääkaupunkiseutu & 386 & 2,18 &, 800 \\
\hline Kaupunkimainen kunta & 1089 & 2,38 & 933 \\
\hline Taajaan asuttu tai maaseutumainen kunta & 406 & 2,37 & 916 \\
\hline
\end{tabular}

Koetko saaneesi riittävästi kannustusta taiteeseen tai muuhun luovaan toimintaan osallistumiseen vanhemmiltasi?**

\begin{tabular}{lccc}
\hline Täysin riittävästi & 913 & 2,38 &, 882 \\
\hline Melko riittävästi & 547 & 2,41 &, 939 \\
\hline En ole kaivannut kannustusta & 157 & 2,06 &, 843 \\
\hline Melko riittämättömästi & 186 & 2,29 &, 936 \\
\hline Täysin riittämättömästi & 97 & 2,07 &, 845 \\
\hline Kulttuuriharrastusten määrä*** & & & \\
Ei yhtään harrastusta & 716 & 2.22 &, 853 \\
\hline 1-2 harrastusta & 714 & 2,32 &, 912 \\
\hline tai useampi harrastus & 470 & 2,55 &, 940
\end{tabular}


Taiteella voi vaikuttaa yhteiskunnallisiin asioihin***

\begin{tabular}{lccc} 
Täysin samaa mieltä & 455 & 2,52 &, 939 \\
\hline Jokseenkin samaa mieltä & 719 & 2,47 &, 903 \\
\hline En osaa sanoa & 69 & 2,14 &, 848 \\
\hline Jokseenkin eri mieltä & 451 & 2,07 &, 769 \\
\hline Täysin eri mieltä & 206 & 2,12 &, 953 \\
\hline Taiteen harrastaminen kasvattaa itsetuntemusta*** & & & \\
\hline Täysin samaa mieltä & 536 & 2,56 &, 933 \\
\hline Jokseenkin samaa mieltä & 854 & 2,34 &, 883 \\
\hline En osaa sanoa & 136 & 2,15 &, 977 \\
\hline Jokseenkin eri mieltä & 235 & 2,12 &, 804 \\
\hline Täysin eri mieltä & 49 & 1,95 &, 855 \\
\hline Taiteesta on taloudellista hyöłyä*** & & \\
\hline Täysin samaa mieltä & 137 & 2,59 &, 992 \\
\hline Jokseenkin samaa mieltä & 527 & 2,44 &, 993 \\
\hline En osaa sanoa & 111 & 2,20 &, 904 \\
\hline Jokseenkin eri mieltä & 843 & 2,33 &, 834 \\
\hline Täysin eri mieltä & 282 & 2,11 &, 842 \\
\hline Taiteesta ei tarvitse olla hyötyä, vaan se on itseisarvo*** & & \\
\hline Täysin samaa mieltä & 437 & 2,43 &, 885 \\
\hline Jokseenkin samaa mieltä & 833 & 2,38 &, 913 \\
\hline En osaa sanoa & 176 & 2,17 &, 881 \\
\hline Jokseenkin eri mieltä & 371 & 2,26 &, 926 \\
\hline Täysin eri mieltä & 83 & 2,10 &, 805 \\
\hline Graffitit tulee ymmärtää taiteena eikä rikoksena*** & & & \\
\hline Täysin samaa mieltä & 424 & 2,45 &, 972 \\
\hline Jokseenkin samaa mieltä & 769 & 2,39 &, 912 \\
\hline En osaa sanoa & 108 & 2,27 &, 804 \\
\hline Jokseenkin eri mieltä & 382 & 2,31 &, 870 \\
\hline Täysin eri mieltä & 217 & 2,20 &, 785 \\
\hline
\end{tabular}

*** $\mathrm{P}<.001$, ** $\mathrm{P}<.01, * \mathrm{P}<.05$

Sosiaalisista taustatekijöistä nuorten korkeakulttuurista suuntautumista ennustavia tekijöitä ovat vanhempien koulutusaste sekä vanhemmilta saatuja kulttuurisia resursseja mittaava muuttuja. Vanhempien koulutusasteen ja korkeakulttuurisen suuntautumisen väliseen yhteyteen vakiointi ei vaikuta ja nuorten korkeakulttuurista suuntautumista ennustavat molempien vanhempien yliopistotutkinto, joiden keskiarvo on korkein. Toisaalta muuttujan betakerroin on ainoastaan 0,71 , joten koulutusasteen ennustusaste jää matalaksi. Vanhemmilta saatuja kulttuurisia resursseja mittaavan muuttujan keskiarvoissa tapahtuu hienoisia muutoksia vakioinnin seurauksena, joskin kan- nustusta riittävästi saaneiden keskiarvot säilyvät korkeimpina. Kannustuksen riittävyys ennustaa nuorten korkeakulttuurista suuntautumista, joskin muuttajan ennustusaste jää verrattain alhaiseksi.

Yksilöllisiä valintoja mittaavista muuttujista lähes kaikki, taiteen itseisarvoa mittaavaa muuttujaa lukuun ottamatta, ennustavat nuorten korkeakulttuurista suuntautumista vahvemmin tai heikommin. Yhteyden säilyttäneiden muuttujien suunta korkeakulttuuriseen suuntautumiseen säilyy samansuuntaisena vakioinnista huolimatta, vaikka vakiointi nostaa ja laskee yksittäisten vastausvaihtoehtojen keskiarvoja. Lisäksi yksilöllisiä valintoja mittaavien muuttu- 
jien ennustusastetta mittaavien betakertoimien arvot ovat korkeampia kuin sosiaalisia taustatekijöitä mittaavien muuttujien. Tulosten mukaan useat kulttuuriharrastukset ennustavat nuorten korkeakulttuurista suuntautumista, sillä vähintään kolmea kulttuuriharrastusta harrastavien nuorten keskiarvo on 2,48. Lisäksi myönteinen suhtautuminen eri taideväittämiin on nuorten korkeakulttuurista suuntautumista ennustava tekijä. Taideväittämien kanssa joko "Täysin samaa mieltä" tai "Jokseenkin samaa mieltä" olevien keskiarvot säilyvät muita vastausvaihtoehtoja korkeampina ja taideväittämien betakertoimet ovat varsin korkeita $(0,93-1,43)$.

\section{Yksilölliset valinnat erottelevat nuorten kulttuurista kiinnostuneisuutta}

Toinen tutkimusasetelma poikkeaa ensimmäisestä sen suhteen, että nyt tarkastelun kohteena on jatkuvan muuttujan sijaan kaksi ryhmää. Ensimmäisessä ryhmässä ovat korkeakulttuuriin suuntautuneet nuoret. Jälkimmäisessä ryhmässä ovat nuoret, jotka eivät ole suuntautuneet korkeakulttuuriin. Erotteluanalyysin avulla tutkitaan, miten eri selittävät muuttujat erottelevat tutkimuksen kohteena olevia ryhmiä toisistaan. Menetelmä luo ryhmien välille erottelu-ulottuvuuden, jossa ovat ryhmiä voimakkaimmin erottelevat muuttujat.

Erotteluanalyysin onnistumisen kannalta on tärkeää, että erottelufunktion tutkittavat

Taulukko 2. Moniluokitteluanalyysin tulokset. (Taulukko jatkuu seuraavalle sivulle.)

Muuttuja $\quad \begin{aligned} & \text { Vakioitu } \\ & \text { keskiarvo Eta }\end{aligned} \quad$ Beta $\begin{aligned} & \text { Poikkeama } \\ & \text { kokonais- } \\ & \text { ka:sta }\end{aligned}$

\section{Vanhempien koulutusaste**}

Ei yliopistotutkintoa

Vain toisella vanhemmista yliopistotutkinto

Molemmilla vanhemmilla yliopistotutkinto

\section{Asuinpaikka}

Pääkaupunkiseutu

Kaupunkimaiset kunnat

Taajaan asutut tai maaseutumaiset kunnat

\section{2,31}

2,34

2,54

2,26

2,37

2,33
, 077

(2)

, 088

Koetko saaneesi riittävästi kannustusta taiteeseen tai muuhun luovaan toimintaan osallistumiseen vanhemmiltasi?**

\begin{tabular}{ll} 
Täysin riittävästi & 2,36 \\
\hline Melko riittävästi & 2,40 \\
\hline En ole kaivannut kannustusta & 2,14 \\
\hline Melko riittämättömästi & 2,28 \\
\hline Täysin riittämättömästi & 2,18 \\
\hline Kulttuuriharrastusten määrä**** & \\
\hline Ei yhtään kulttuuriharrastusta & 2,24 \\
\hline 1-2 kulttuuriharrastusta & 2,34 \\
Vähintään kolme kulttuuriharrastusta & 2,48
\end{tabular}

Taiteella voi vaikuttaa yhteiskunnallisiin asioihin***

Täysin samaa mieltä

Jokseenkin samaa mieltä

En osaa sanoa

Jokseenkin eri mieltä

2,45

2,43

2,21

Täysin eri mieltä

2,36

\begin{tabular}{|c|c|}
\hline \multirow{3}{*}{,071, } &,- 03 \\
\hline & ,00 \\
\hline & 21 \\
\hline \multirow{3}{*}{,043 } &,- 07 \\
\hline & ,03 \\
\hline &,- 00 \\
\hline
\end{tabular}

$-, 03$

21

07

$-, 00$ 
Taiteen harrastaminen kasvattaa itsetuntemusta***

\begin{tabular}{ll} 
Täysin samaa mieltä & 2,49 \\
\hline Jokseenkin samaa mieltä & 2,32 \\
En osaa sanoa & 2,36 \\
Jokseenkin eri mieltä & 2,15 \\
Täysin eri mieltä & 2,15
\end{tabular}

2,49

2,32

2,36

2,15

2,15

Taiteesta on taloudellista hyötyä ${ }^{* * *}$

$\begin{array}{ll}\text { Täysin samaa mieltä } & 2,53 \\ \text { Jokseenkin samaa mieltä } & 2,41 \\ \text { En osaa sanoa } & 2,29 \\ \text { Jokseenkin eri mieltä } & 2,32 \\ \text { Täysin eri mieltä } & 2,19\end{array}$

Taiteesta ei tarvitse olla hyötyä, vaan se on itseisarvo

\begin{tabular}{ll} 
Täysin samaa mieltä & 2,34 \\
\hline Jokseenkin samaa mieltä & 2,37 \\
En osaa sanoa & 2,26 \\
Jokseenkin eri mieltä & 2,34 \\
Täysin eri mieltä & 2,1
\end{tabular}

\section{Graffitit tulee ymmärtää taiłeena eikä rikoksena**}

Täysin samaa mieltä
Jokseenkin samaa mieltä
En osaa sanoa
Jokseenkin eri mieltä
Täysin eri mieltä
$* * * \mathrm{P}<.001, * * \mathrm{P}<.01, * \mathrm{P}<.05$
Selitysaste $\mathrm{R}^{2}:, 119$
Yhteiskorrelaatio $\mathrm{R}:, 344$
Mittarin kokonaiskeskiarvo: 2,34

ryhmät eroavat toisistaan tilastollisesti merkitsevästi (Jokivuori \& Hietala 2007, s. 126). Analyysin tuottaman Wilksin lambdan mukaan funktion p-arvo on ,000 (Räisänen 2014, s. 63), mikä tarkoittaa, että ryhmät eroavat toisistaan tarpeeksi voimakkaasti. Erottelu-ulottuvuuden ensimmäisessä päässä ovat korkeakulttuuriin suuntautuneet nuoret, joiden painopisteeksi tulee ,409. Nuoret, jotka eivät ole korkeakulttuuriin suuntautuneita, sijoittuvat erottelu-ulottuvuuden toiseen päähän. Heidän painopisteensä on -,229. Erottelufunktion muuttujien kanoniset korrelaatiot kuvaavat muuttujien etäisyyttä erottelu-ulottuvuuden keskipisteestä. Tutkittavia ryhmiä voimakkaasti erottelevat muuttujat sijaitsevat mahdollisimman kaukana keskipisteestä.
Erottelufunktiolle tulevien muuttujien kanoniset korrelaatiot esitetään Taulukossa 3. Sen mukaan seitsemän muuttujaa erottelee nuorten korkeakulttuurista suuntautumista. Muuttujista yksi liittyy sosiaalisiin taustatekijöihin ja kuusi yksilöllisiin valintoihin. Ryhmiä erottelemattomia muuttujia ovat nuoren sukupuoli, opiskelupaikka, asuinpaikka ja vanhempien koulutus.

Sosiaalisista taustatekijöistä tutkittavia ryhmiä erottelee vanhemmilta saatuja kulttuurisia resursseja mittaava muuttuja. Korkeakulttuurisesti suuntautuneet nuoret kokevat saavansa vanhemmiltaan riittävästi kannustusta taiteelliseen tai muuhun luovaan toimintaan osallistumiseen. Vastaavasti nuoret, jotka eivät ole korkeakulttuurisesti suuntautuneita, kokevat 
saavansa kannustusta riittämättömästi.

Yksilöllisiä valintoja mittaavista muuttujista tutkittavia ryhmiä erottelee kulttuuriharrastusten määrä sekä kaikki taiteeseen liittyvistä asenneväittämistä. Korkeakulttuuriin suuntautuneille nuorille on tyypillistä useat kulttuuriharrastukset. Sen sijaan vähän kulttuuria harrastavat lukeutuvat nuoriin, jotka eivät ole korkeakulttuurisesti suuntautuneita. Eri taideväittämät erottelevat tutkittavia ryhmiä yhdenmukaisesti. Myönteinen suhtautuminen taideväittämiin yhdistää korkeakulttuurisesti suuntautuneita nuoria. Vastaavasti korkeakulttuuriin suuntautumattomille on tunnusomaista kielteinen suhtautuminen esitettyihin taideväittämiin.

\section{Tutkimusasetelmien tuloksissa yhdenmukaisuutta}

Tutkimusasetelmista saadut tulokset ovat varsin yhdenmukaisia. Niiden mukaan yksilöllisillä valinnoilla on sosiaalisia taustatekijöitä voimakkaampi vaikutus nuorten korkeakulttuuriseen suuntautumiseen.

Tutkimuksessa yksilöllisiä valintoja mitattiin nuoren kulttuuriharrastusten määrällä sekä suhtautumisella erilaisiin taideväittämiin. Molemmat tutkimusasetelmat osoittavat, että useat kulttuuriharrastukset ovat tyypillisiä korkeakulttuuriin suuntautuneille nuorille. Lisäksi molempien tutkimusasetelmien mukaan myönteinen suhtautuminen taiteen moninaisia merkityksiä kohtaan yhdistää korkeakulttuuriin suuntautuneita nuoria.

Sosiaaliset taustatekijät vaikuttavat heikosti nuorten korkeakulttuuriseen suuntautumiseen. Nuoren asuinpaikalla, iällä, opiskelupaikalla tai sukupuolella ei havaittu olevan yhteyttä korkeakulttuuriseen suuntautumiseen kummassakaan tutkimusasetelmassa. Ensimmäisessä tutkimusasetelmassa molempien vanhempien yliopistotason koulutuksen havaittiin ennustavan heikosti nuorten korkeakulttuurista suuntautumista, mutta toisessa tutkimusasetelmassa vanhempien koulutuksen ei havaittu erottelevan tutkittavia ryhmiä.

Sosiaalisten taustatekijöiden osalta ainoastaan vanhemmilta saatuja kulttuurisia resursseja mittaavalla muuttujalla havaittiin olevan yhteys korkeakulttuuriseen suuntautumiseen molemmissa tutkimusasetelmissa. Vanhemmilta saatuja kulttuurisia resursseja mitattiin vanhemmilta saadulla kannustuksella taiteeseen tai muuhun luovaan toimintaan osallistumiseen. Molemmissa tutkimusasetelmissa havaittiin, että kannustuksen riittävyys on yhteydessä korkeakulttuuriseen suuntautumiseen. Kuitenkin muuttujan ennustusaste ja sen erottelukyky jää-

\section{Taulukko 3. Erottelufunktio ja sen sisältämät muuttujat}

1. $\begin{aligned} & \text { Taiteen harrastaminen kasvattaa itsetuntemusta } \\ & \text { (eri mieltä - samaa mieltä) }\end{aligned}$
$\begin{aligned} & \text { Taiteella voi vaikuttaa yhteiskunnan asioihin } \\ & \text { (eri mieltä - samaa mieltä) }\end{aligned}$
$\begin{aligned} & \text { Kulttuuriharrastusten määrä } \\ & \text { Taiteesta ei tarvitse olla hyötyä, vaan se on itseisarvo }\end{aligned}$
$\begin{aligned} & \text { Graffitit tulee ymmärtää taiteena eikä rikoksena } \\ & \text { (eri mieltä - samaa mieltä) }\end{aligned}$
$\begin{aligned} & \text { Koetko saaneeni riittävästi kannustusta taiteeseen tai muuhun luovaan toimin- } \\ & \text { taan osallistumiseen vanhemmiltasi? (riittämättömästi - riittävästi) }\end{aligned}$
$\begin{aligned} & \text { Taiteesta on taloudellista hyöytä } \\ & \text { (eri mieltä - samaa mieltä) }\end{aligned}$


vät useita yksilöllisiä valintoja mittaavia muuttujia heikommaksi.

\section{Nuorten kulttuurivalinnat eivät ole itsestään selviä}

Yksilöllisten valintojen vaikutusta korostava tulos on johdonmukainen viimeaikaisten keskustelujen kanssa. Muuan muassa väitteet nuorten elämäntyylien atomisoitumisesta (Salasuo 2006, s. 31) näyttäisivät saavan tukea tarkasteltaessa suomalaisten nuorten korkeakulttuurisen suuntautumiseen vaikuttavia tekijöitä, vaikkakin kyseessä on varsin kapeaalainen osa lukuisista joukoista elämäntyylejä, joita nuoret nykyään edustavat. Tämän lisäksi tulos on linjassa uudempien kulttuurisosiologisten tutkimusten kanssa, joiden mukaan (esim. Daenekindt \& Roose, 2013; Hanquinet, 2013; Lahire, 2008) kulttuuristen tyylien ja kulttuurivalintojen muodostumisessa erinäisillä yksilöllisillä valinnoilla, kuten kulttuurisilla kiinnostuksenkohteilla tai taiteelle annetuilla merkityksenannoilla, on entistä suurempi merkitys.

Sen sijaan tulokset näyttäisivät puhuvan aikaisempia käsityksiä vastaan, jotka korostavat erilaisten sosiaalisten taustatekijöiden, kuten perhetaustan (Nagel, 2010), nuoren sukupuolen (van Wel ym., 2006) tai koulutusasteen (Willekens \& Lievens, 2014), merkitystä suomalaisten nuorten korkeakulttuurisen suuntautumisen muodostumiseen. Erityisesti perhetaustan vaikutuksen heikkous on yllättävää, sillä juuri vanhempien korkeakoulutusta ja heiltä saatuja kulttuurisia resursseja on aiemmin pidetty keskeisinä nuorten korkeakulttuuriseen suuntautumiseen vaikuttavina tekijöinä (Nagel, 2010; Nagel ym., 2010; Willekens \& Lievens, 2014). Toisaalta suomalaisessa yhteiskunnassa koko väestön korkeakulttuurin kuluttamista selittää voimakkaimmin koulutuksen sijaan sukupuoli ja ikä (Alasuutari, 2009; Purhonen ym., 2011; Rahkonen \& Purhonen, 2004). Korkeakoulutuksen vähäisempi merkitys voikin osaltaan selittää, miksi vanhempien koulutus ei näyttele niin tärkeää osaa nuorten korkeakulttuurisen suuntautumisen muodostumiseen Suomessa. Vanhemmilta saatujen kulttuuristen resurssien ja nuorten korkeakulttuurisen suuntautumisen välisen heikon yhteyden taustalla voi olla se, että nuoret hankkivat kulttuurisia tietoja myös itsenäisesti tai omien kavereidensa ja muiden verkostojensa kautta. Yhdessä tekeminen kavereiden kanssa, ja niistä saaduilla kokemuksilla tai internetistä hankituilla tiedoilla voi olla vanhempia suurempi merkitys nuorten kulttuurivalintojen muodostumiseen.

Toisaalta vanhemmilta saatuja kulttuurisia resursseja mitattiin tässä tutkimuksessa vanhemmilta saadulla kannustuksella taiteelliseen tai muuhun luovaan toimintaan osallistumiseen, mikä on yksi tapa vanhemmilta saatujen kulttuuristen resurssien vaikutusten mittaamiseen (Scherger \& Savage, 2010). Niiden vaikutusta tulisi lähestyä myös muista tarkastelukulmista, kuten vanhempien taidelaitoksissa ja kulttuuritapahtumissa käymisen näkökulmasta (vrt. Nagel, 2010). Tarkastelukulman laajentaminen tarjoaisi monipuolisempaa tietoa vanhemmilta saatujen kulttuuristen resurssien vaikutuksesta nuorten kulttuurivalintojen muodostumiseen. Tässä tutkimuksessa käytettävä aineisto ei kuitenkaan mahdollistanut tällaisen tarkastelukulman mukaanottoa.

Vaikka tutkimuksen tulokset korostavat yksilöllisten valintojen merkitystä suomalaisten nuorten korkeakulttuurisen suuntautumisen muodostumiselle, niin tuloksista ei välttämättä kannata tehdä liian pitkälle meneviä johtopäätöksiä nuorten kulttuurivalintojen yksilöllistymisen suhteen, sillä tutkimukseen valittu lähestymistapa mittaa nuoren subjektiivista kokemusta eri kulttuuri- ja taidelaitosten tärkeydestä, eikä niissä käymisen aktiivisuutta, mihin nuoren perhetaustan (Nagel, 2010) sukupuolen (van Wel ym., 2006) ja koulutuksen (Willekens \& Lievens, 2014), on muissa maissa tehdyissä tutkimuksissa havaittu vaikuttavan. Lähestymistavan erilaisuus voikin osaltaan selittää tuloksen poikkeavuutta suhteessa aikaisempiin tutkimuksiin. Sosiaaliset rakenteet, kuten nuoren asuinpaikkakunnan kulttuuri- ja taidelaitosten tarjonta tai niiden pääsylippujen hinnat, luovat osallistumi- 
sen esteitä kulttuuri- ja taidelaitoksissa käymiseen, mutta nämä esteet eivät välttämättä näy nuorten subjektiivisissa asenteissa. Nuori saattaa kokea kulttuuri- ja taidelaitokset tärkeiksi, vaikka hänen mahdollisuutensa niissä käymiseen olisivat satunnaisia. Tällaisen tulkinnan tekeminen tarkoittaisi, että kulttuurivalintojen tutkimuksen tulokulmaa tulisi laa- jentaa niin, että se huomioisi kulttuuriosallistumisen eri ulottuvuudet, kuten kulttuurinkulutuksen sekä kulttuurille annetut subjektiiviset merkityksenannot entistä paremmin. Tutkimuksen tulokulman laajentaminen antaisi entistä vahvempaa tietoa sosiaalisten tekijöiden ja yksilöllisten valintojen vaikutuksesta nuorten kulttuurivalintoihin.

\section{Kirjallisuus}

Alasuutari, P. (2009). Snobismista kaikkiruokaisuuteen: musiikkimaku ja koulutustaso. Teoksessa M., Liikkanen (toim.), Suomalainen vapaa-aika. Arjen ilot ja valinnat (81-100). Helsinki: Gaudeamus.

Bourdieu, P. (1984). Distinction: a social critique of the judgment of taste. Cambridge, United States of America: Harvard University Press.

Christin, A. (2012). Gender and highbrow cultural participation in the United States. Poetics, 40 (5), 423-443.

Daenekindt, S. \& Roose, H. (2013). Cultural chameleons: Social mobility and cultural practices in the private and the public sphere. Acta Sociologica, 56 (4), 309-324.

Daenekindt, S. \& Roose, H. (2014). Social mobility and cultural dissonance. Poetics, 42 (1), 82-97.

Eijck, K. van (1997). The impact of family background and educational attainment on cultural consumption: A sibling analysis. Poetics, 25 (4), 195-224.

Eijck, K. van \& Bargeman, B. (2004). The changing impact of social background on lifestyle: "culturalization" instead of individualization? Poetics, 32 (6), 439-461.

Eijck, K. van \& Knulst, W. (2005). No More Need for Snobbism: Highbrow Cultural Participation in a Taste Democracy. European Sociological Review, 21 (5), 513-528.

Gripsrud, J., Hovden, J., F. \& Moe, H. (2011). Changing relations: Class, education and cultural capital. Poetics, 39 (6), 507-529.

Hanquinet, L. (2013). Visitors to modern and contemporary art museums: towards a new sociology of "cultural profiles". The Sociological Review, 61 (4), 790-831.
Jokivuori, P. \& Hietala, R. (2007). Määrällisiä tarinoita. Monimuuttujamenetelmien käyttö ja tulkinta. Porvoo, Suomi: WSOY.

Lahire, B. (2008). The individual and the mixing of genres: Cultural dissonance and selfdistinction. Poetics, 36 (2-3), 166-188.

Nagel, I. (2010). Cultural Participation Between the Ages of 14 and 24: Intergenerational Transmission or Cultural Mobility? European Sociological Review, 26 (5), 541-556.

Nagel, I., Damen, M. \& Haanstra, F. (2010). The arts course CKV1 and cultural participation in the Netherlands. Poetics, 38 (4), 365-385.

Nagel, I. \& Ganzeboom H. (2002). Participation in Legitimate Culture: Family and School Effects from Adolescence to Adulthood. The Netherlands' Journal of Social Sciences, 38 (2), 102-120.

Nummenmaa, L. (2010). Käyttöytymistieteiden tilastolliset menetelmät. Helsinki, Suomi: Tammi.

Nuorisobarometri (2009) [elektroninen aineisto]. FSD2484, versio 1.0 (2009-1 1-26). Helsinki: Innolink Research [aineistonkeruu], 2009. Helsinki: Opetusministeriö. Nuorisoasiain neuvottelukunta (NUORA) \& Helsinki: Nuorisotutkimusseura. Nuorisotutkimusverkosto [tuottajat]. Tampere: Yhteiskuntatieteellinen tietoarkisto [jakaja], 2009.

Peterson, R., A. \& Kern, R., M. (1996). Changing Highbrow Taste: From Snob to Omnivore. American Sociological Review, 61 (5), 900-907.

Purhonen S. (2011). Televisiokatselun sosiaalinen eriytyminen ja yhteiskunnalliset seuraukset nyky-Suomessa. Yhteiskuntapolitiikka, 76 (5), 599-619. 
Purhonen S., Gronow, J. \& Rahkonen, K. (2011). Highbrow culture in Finland: Knowledge, taste and participation. Acta Sociologica, 54 (4), 385-402.

Rahkonen, K. \& Purhonen, S. (2004). Kulttuuripääoma ja hedonistinen kuluttaminen Suomessa Empiriisesti orientoitunut jälkikirjoitus 1990-luvun kulutussosiologiaan. Teoksessa P., Jokivuori \& P., Ruuskanen (toim.), Arjen talous: Talous, tunteet ja yhteiskunta (157-184). Jyväskylä: Minerva.

Roose, H., Koen van, E. \& Lievens, J. (2012). Culture of distinction or culture of openess? Using a social space approach to analy the social structuring of lifestyles. Poetics, 40 (6), 491513.

Räisänen P. (2014). Nuorten yksilöllistyvät kulttuurivalinnat: Tutkimus sosiaalisten taustatekijöiden ja yksilöllisten valintojen vaikutuksesta nuorten kulttuuri- ja taidelaitosten tärkeinä pitämiseen. Pro gradu -tutkielma. Jyväskylä: Jyväskylän yliopisto.

Scherger, S. \& Savage, M. (2010). Cultural transmission, educational attainment and social mobility. The Sociological Review, 58 (3), 406-428.

Salasuo, M. (2006). Atomisoitunut sukupolvi. Pääkaupunkiseudun nuorisokulttuurinen maisema ja nuorisotyön haasteita 2000-luvun alussa. Helsigin kaupungin tutkimuksia 2006:6. Helsinki: Helsingin kaupungin tietokeskus.

Tanner, J., Asbridge, M. \& Wortley, S. (2008). Our favourite melodies: Musical consumption and teenage lifestyles. British Journal of Sociology, 59 (1), 117-144.

Wel, F. van, Couwenbergh-Soeterboek, N., Couwenbergh, C., Bogt, T. ter \& Raaijmakers, Q. (2006). Ethnicity, youth cultural participation, and cultural reproduction in the Netherlands. Poetics, 34 (1), 65-82.

Wel, F. van, Maarsingh, W., Bogt, T. ter \& Raaijmakers, Q. (2008). Youth cultural styles. From snob to pop? Young, 16 (3), 325-340.

Willekens, M. \& Lievens, J.(2014). Family (and) culture: The effect of cultural capital within the family on the cultural participation of adolescents. Poetics, 42 (1), 98-1 13. 
Liite 1. Klusteroitavien muuttujien varianssianalyysin tulokset.

\begin{tabular}{|c|c|c|c|c|c|c|}
\hline \multirow{2}{*}{ Kulttuuri- tai taidelaitos } & \multicolumn{2}{|l|}{ Cluster } & \multicolumn{2}{|l|}{ Error } & \multirow[t]{2}{*}{$\mathbf{F}$} & \multirow[t]{2}{*}{ Sig. } \\
\hline & Mean Square & Df & Mean square & df & & \\
\hline $\begin{array}{l}\text { Oopperaesitykset ja ooppe- } \\
\text { rajuhlat }\end{array}$ & 302,868 & 1 & 0,862 & 1898 & 351,158 &, 000 \\
\hline Taidemuseot ja taidenäyttelyt & 1682,759 & 1 & 0,864 & 1898 & 1948,656 &, 000 \\
\hline $\begin{array}{l}\text { Kulttuurihistorialliset museot ja } \\
\text { näyttelyt }\end{array}$ & 1916,368 & 1 & 0,863 & 1898 & 2220,685 & 000 \\
\hline Teatteriesitykset & 910,003 & 1 & 1,534 & 1898 & 593,370 &, 000 \\
\hline $\begin{array}{l}\text { Sinfonia- ja kamarimusiikkiesi- } \\
\text { tykset }\end{array}$ & 948,700 & 1 & 1,243 & 1898 & 763,209 &, 000 \\
\hline $\begin{array}{l}\text { Kulttuuri- ja taidetalojen } \\
\text { palvelut }\end{array}$ & 950,467 & 1 & 1,452 & 1898 & 654,753 &, 000 \\
\hline
\end{tabular}

Liite 2. Yksittäisten kulttuuri- tai taidelaitoksen saamat klusteripisteet.

\begin{tabular}{lcc|} 
Kulttuuri- tai taidelaitos & \multicolumn{3}{c}{$\begin{array}{c}\text { Klusteri } \\
\text { Kulttuuri- ja taidelaitokset } \\
\text { eivät tärkeitä }\end{array}$} & $\begin{array}{c}\text { Kulttuuri- ja taidelaitokset } \\
\text { tärkeitä }\end{array}$ \\
\hline Oopperaesitykset ja oopperajuhlat & 1,28 & 2,12 \\
\hline Taidemuseot ja taidenäyttelyt & 1,65 & 3,61 \\
\hline Kulttuurihistorialliset museot ja näyttelyt & 1,71 & 3,80 \\
\hline Teatteriesitykset & 2,49 & 3,93 \\
\hline Sinfonia- ja kamarimusiikkiesitykset & 1,47 & 2,94 \\
\hline Kulttuuri- ja taidetalojen palvelut & 2,09 & 3,57 \\
\hline N & $\mathbf{1 2 1 6}$ & $\mathbf{6 8 4}$
\end{tabular}

Liite 3. Erotteluanalyysin tuottama funktio.

\begin{tabular}{ccccc|} 
Funktio & Ominaisarvo & Erottelukyky (\%) & $\begin{array}{c}\text { Erottelukyky } \\
\text { kumulatiivinen }\end{array}$ & Kanoninen korrelaatio \\
\hline 1 &, 094 & 100,0 & 100,0 &, 293 \\
\hline
\end{tabular}

Liite 4. Wilks' Lambda.

\begin{tabular}{ccccc}
$\begin{array}{c}\text { Test of Func- } \\
\text { tion(s) }\end{array}$ & Wilks' Lambda & Chi-square & Df & Sig. \\
\hline 1 &, 914 & 167,835 & 7 &, 000
\end{tabular}

